\title{
Cidadania cultural
}

\section{Cultural citizenship}

\section{RESUMO}

É chegado o momento do conceito de cidadania cultural. Dando seguimento à cidadania política - o direito de residir e votar - e à cidadania econômica - o direito de progredir e prosperar -, a cidadania cultural pleiteia o direito à comunicação e à representação da diferença cultural.

Palavras-chave: cultura, cidadania, teoria política

\section{ABSTRACT}

Cultural citizenship is a concept whose time has come. Following on from political

* Professor da University of California, Riverside. Seus livros mais recentes são Television Studies: The Basics (2010), The Contemporary Hollywood Reader (2009) e Makeover Nation: The United States of Reinvention (2008). Seus trabalhos podem ser lidos em tobymiller.org. citizenship - the right to reside and to vote - and economic citizenship - the right to thrive and prosper - it insists on a right to communication and to the representation of cultural difference.

Keywords: culture, citizenship, political theory 
As Constituições liberais europeias do século XIX eram Constituições políticas... As Constituições do primeiro terço do século XX... eram dedicadas às questões econômicas e sociais... na década de 1970, entra em evidência um novo patamar com a aparição de questões de caráter cultural: isso gera formas léxicas e categorias doutrinárias tais como "direitos culturais"... a livre existência da cultura, o pluralismo cultural e o acesso dos cidadãos à cultura são garantidos mediante formas intensificadas - Jesús Prieto de Pedro (1999: 63)

S ÚLTIMOS DUZENTOS anos da época moderna produziram três áreas de cidadania cujas historicidades coincidem em parte, mas também divergem. Essas áreas de cidadania são

- a política (que confere o direito de residir e votar)

- a econômica (o direito de progredir e prosperar); e

- a cultural (o direito ao conhecimento e à expressão)

Essas áreas correspondem ao apelo da Revolução Francesa "liberté, égalité, fraternité" e à versão contemporânea da esquerda argentina "ser ciudadano, tener trabajo y ser alfabetizado" (Martín-Barbero, 2001: 9). A primeira categoria está relacionada a direitos políticos; a segunda, a interesses materiais; e a terceira, à representação cultural (Rawls, 1971: 61).

Obviamente, a cidadania sempre foi uma questão cultural. O Império Otomano, por exemplo, oferecia aos não-muçulmanos "muitos direitos culturais, mas poucos direitos políticos" (Parekh, 2000: 7). As primeiras garantias constitucionais à cultura ocorreram na Suíça em 1874. Atualmente, as provisões culturais são a regra nas Constituições pós-ditadura como, por exemplo, no México, África do Sul, Brasil, Portugal, Guatemala, Nicarágua, Paraguai, Peru e Espanha. O significado é geralmente duplo, combinando as formas artísticas e a etnicidade. Assuntos relacionados a idioma, patrimônio cultural, religião e identidade são respostas a histórias estruturadas na dominação por meio do poder cultural e na incorporação pós-colonial da periferia em um sistema internacional de trabalho livre. A Malásia, por exemplo, tem sido predominantemente islâmica há séculos. $\mathrm{O}$ colonialismo atraiu para lá um grande número de sul-asiáticos e chineses com suas respectivas religiões. A Constituição póscolonial concede um status especial para os malaios étnicos e para o Islã, mas também protege os direitos culturais do restante da população. Os muçulmanos são os únicos com direito a evangelizar e contam com tribunais religiosos. Outras variedades de crença são toleradas, mas não têm direito ao proselitismo e são regidas por normas seculares (Miller, 2007a).

Na Holanda, Sudão, Iêmen, Eslovênia, Bahrein e Portugal, a cidadania baseia-se nas competências linguísticas. Na Suécia e no Sudão, ela depende 
da condução de "uma vida respeitável" e de ter "um bom caráter moral", respectivamente. $\mathrm{O}$ "apego" à cultura local é um dos critérios na Croácia; e na Romênia, o conhecimento da cultura e da história locais. A Libéria exige que os cidadãos "preservem, fomentem e mantenham a cultura positiva liberiana", algo que se considera que somente "as pessoas de raça negra ou descendentes de negros" podem fazer. A cidadania baseada em raça também é aplicada em Serra Leoa, e Israel restringe a cidadania aos judeus, além dos árabes que tenham vivido lá desde antes de 1948 e seus descendentes. Preferências raciais e religiosas parciais também regem o Bahrein e o Iêmen. Não é de admirar que a proposta do governo britânico, anunciada em 2002, de impor um requisito linguístico de conhecimento de inglês, galês ou gaélico escocês aos aspirantes à cidadania tenha provocado críticas iradas por parte da população não-branca, para a qual a proposta foi claramente pensada com fins de exclusão, mesmo que seus defensores a considerassem uma prova de aptidão para a vida cotidiana no país. Também não surpreende que tenha fracassado a tentativa do Estado argentino de reprimir formações culturais não europeias por meio de uma variedade de tecnologias culturais estranhas, desde exigir que todos os alunos cobrissem suas roupas com um guarda-pó branco até proibir línguas indígenas (Miller, 2007b).

O cidadão liberal modelo é um sujeito esclarecido e despojado que sabe quando deixar de lado preferências individuais e sectárias em prol do bem comum. Isso pode parecer imparcial e livre de dimensão cultural; talvez neutro. Mas, historicamente, este modelo correspondeu frequentemente, tanto em termos retóricos quanto legais, a indivíduos do sexo masculino e proprietários que, para proteger seus interesses do resto da população em geral, estabeleciam como requisito a renúncia pública a outras lealdades, o apoio inquestionável às ideologias nacionalistas e um aparente autocontrole sobre os desejos pessoais. Isso levou a qualificações profundamente culturais para uma zona supostamente livre de qualquer dimensão cultural - o governo dos Estados Unidos. Muitos liberais filosóficos defendem um idioma e uma nação comuns como pré-requisitos para uma cidadania efetiva. Mas as diferenças culturais colocam em dúvida o que uma "vida devidamente ordenada" pode significar em nações divididas por línguas, religiões e sentidos de identidade de populações migrantes. Como afirma o teórico político Will Kymlicka, "não é que as doutrinas tradicionais dos direitos humanos nos ofereçam a resposta errada para estas questões. O problema é, sobretudo, que elas nunca oferecem uma resposta. $O$ direito à livre expressão não estabelece em que consiste uma política linguística apropriada" (1995: 5). A insistência de Theodore Roosevelt em uma "assimilação rápida do estrangeiro" por meio do "idioma e cultura 
que herdamos dos construtores da república" (citado em Parekh 2000: 5) parece impraticável, uma desacertada armação ideológica. Essas questões já não podem mais ser decididas à força ou por decreto. Os Estados Unidos são incapazes de sustentar o nacionalismo cultural de um "Paraíso Monolíngue" (Fuentes 2004: 79).

Quando, há um século, os Estados Unidos tentaram impedir que os sinoamericanos obtivessem passaportes, exigiu-se que os candidatos falassem inglês, observassem os "costumes e maneira de vestir norte-americanos" e demonstrassem conhecimento da história e geografia nacionais. Atualmente, tornar-se um cidadão dos Estados Unidos, a não ser que seja por nascimento ou laços sanguíneos, além de ser necessário nunca ter cometido um assassinato ou nunca ter sido flagrado em posse de mais quantidade de maconha que a necessária para uso pessoal imediato, deve-se cumprir com alguns requisitos culturais:

- residir no território

- renunciar à lealdade e obediência a outros Estados

- apoiar a Constituição

- conhecer a histórica política básica do país

- ler, escrever e falar palavras de uso habitual do idioma inglês

- abster-se da poligamia

- participar de jogos de azar somente de maneira legal e

- não frequentar profissionais do sexo e nem embebedar-se repetidamente em público

Para se alistar nas forças armadas dos Estados Unidos não é necessário ser cidadão norte-americano - obter a cidadania é um benefício potencial que atrai recrutas -, mas há diversos requisitos culturais, tais como não ter tatuagem nas mãos ou no rosto, não ter filhos fora do matrimônio e não ter mais de dois filhos dentro do matrimônio (só recentemente foi incorporada à lista a exigência de não possuir nenhuma condenação por violência doméstica). $O$ Serviço de Cidadania e Imigração utiliza estes critérios para determinar "se um solicitante dispõe de um bom caráter moral”. Portanto, estou contente com meu Green Card.

Está claro que à medida que a globalização impõe e convida à mobilidade, as práticas culturais proliferam, dividem-se e fazem polinização cruzada. Com pouco tempo para "processos de aculturação e assimilação" (Castles e Davidson 2000: vii), uma mescla volátil de hibridismo e primordialidade emerge. Seria excessivo tomar esse fato como algo inteiramente novo - já em 1916 o filósofo pragmatista rebelde Randolph Bourne cunhou o termo "América Transnacional" (Portes 2001: 182-83, 185) e combinações do moderno e do tradicional são constitutivos da América Latina - mas parece como se, agora, 
existissem cada vez mais indivíduos e organizações transnacionais, tecendo um amálgama de relações políticas, econômicas e culturais entre seus lugares de origem e os de domicílio. Existe uma diferença crucial entre o início do período moderno no qual a cidadania contemporânea foi forjada, quando o Ocidente provisionava ao Terceiro Mundo migrantes indesejáveis e belicosos, e o período posterior aos anos 1950, quando o processo se reverteu (com intenções muito menos beligerantes). A imigração e o multiculturalismo do final do século XX colocaram em dúvida a concepção tradicional de cidadania naturalizada. É uma questão de pertencimento cultural e desigualdade material.

A "história de indivíduos e mesmo de continentes inteiros como a Europa agora está sendo reescrita em termos de uma formação cultural definida por algo externo a elas, o outro" (Halliday 2001: 113). Emerge uma cidadania global, pós-nacional ou transnacional. À diferença das antigas utopias de cidadania mundial, estes termos são mecanismos heurísticos para descrever formações já existentes, mais além de meros sinais para satisfazer desejos. E os direitos culturais transnacionais emergiu como um campo de batalha. Os delegados da Declaração Universal dos Direitos Humanos estiveram completamente divididos, com Estados Unidos e Canadá opondo-se agressivamente à consagração dos direitos minoritários. Atualmente, um discurso em desenvolvimento dos direitos humanos nacionais e internacionais transcende fronteiras, com a Comissão dos Direitos Humanos reconhecendo os direitos culturais em 2002.

A maioria dos trabalhadores migrantes em todo o mundo não faz parte da classe capitalista ou assalariada. Eles são empregados "temporários" ou "sem documentos", nem cidadãos, nem imigrantes. Uma vez mais, a cultura é fundamental. As identidades destes trabalhadores estão muito separadas tanto de seus domicílios quanto de suas fontes de sustento e, frequentemente, a garantia de um tratamento justo lhes é dada não por parte dos Estados soberanos, mas por meio do discurso supranacional dos direitos humanos e das crenças e costumes cotidianos que complementam as obrigações legais da cidadania convencional. As novas condições de cidadania não estão necessariamente articuladas com a democracia, porque os sujeitos do mercado internacional de trabalho frequentemente não têm acesso às bases de poder dos filhos dos nativos. Na Argentina, por exemplo, que possui uma mão-de-obra migrada da Bolívia e do Peru para realizar trabalhos subalternos, a esquerda tenta garantir proteção para os "trabalhadores convidados", argumentando que os direitos conquistados após a ditadura deveriam ser estendidos a todos os residentes, mesmo que o Estado culpe esses trabalhadores convidados pela recrudescência de doenças "pré-modernas" constrangedoras, como tuberculose e sarampo. $\mathrm{Na}$ União Européia, a criação da "cidadania supranacional", em 1992, deixou em 
evidência o quanto é problemático associar o conceito de cidadania com o de cultura nacional. Mas ao mesmo tempo em que se reconheceu uma nova divisão internacional do trabalho, movimentos equivalentes limitaram os direitos dos trabalhadores procedentes de nações não-européias, que há muito tempo representam a grande maioria da força de trabalho internacional dentro da União.

Enquanto tanto os críticos conservadores quanto os defensores do culturalismo explicam a cidadania cultural como o resultado de movimentos sociais, ela também deve ser entendida como uma adaptação às transformações econômicas; o projeto de desregulamentação promovido pela direita teve um papel importante na criação e sustentação da cidadania cultural. Não surpreende que o empenho para que o Terceiro Mundo se convertesse em um lugar de patrimônio cultural divertido e playground decadente para o Ocidente tenha tido como resultado o surgimento do turismo sexual e do terrorismo (Downey e Murdock 2003: 84). Globalmente, a cidadania cultural é fruto de uma mão-de-obra cada vez mais móvel proveniente da classe média e ligada à indústria cultural. Domesticamente, a cidadania cultural e a desregulamentação da mídia são coeficientes da globalização, oferecendo tanto matéria-prima para exportação como um meio de controle local.

\section{SETE GRUPOS}

Esse complexo quadro político constitui o pano de fundo para o conceito da cidadania cultural. O fenômeno foi teorizado por sete grupos principais, todos eles contando com a esfera pública como elemento essencial de seu argumento.

Em primeiro lugar está Tony Bennett, sociólogo especializado em estudos culturais, e seus colegas do movimento anglo-australiano de estudos de políticas culturais, que enfocam um conjunto de competências garantidas que os governos deveriam proporcionar aos cidadãos por meio de capital artístico. Bennett apoia as dinâmicas de progresso e disseminação que respeitem os conhecimentos populares, tomando emprestado do ideário liberal o princípio de que a forma mais efetiva de governo administra por meio de indivíduos livres que devem receber as ferramentas para viver de maneira tanto autônoma quanto social. Seus principais interlocutores são as burocracias culturais da Austrália e o Conselho Europeu; e seus admiradores incluem progressistas em busca de influência para além dos protestos e críticas afetivos (Bennett, 1998 e 2001). Apesar de cético em relação aos protestos lúdicos contra o Estado e o capital, Bennett admite que as identidades dos movimentos sociais devem ser reconhecidas pelo Estado liberal moderno. Essa linha de pensamento acredita nas oportunidades econômicas proporcionadas pela globalização $e$ na necessidade do patrimônio cultural local tanto para combatê-las quanto para participar delas. 
Em segundo lugar está o antropólogo latino Renato Rosaldo e seus colegas em estudos sobre chican@s, tejan@s ${ }^{1}$, étnicos e latin@s da Califórnia, Texas e Nova York. Esse grupo exige uma série de direitos para as minorias dos Estados Unidos a partir de uma realidade local e cotidiana, com o objetivo de "estabelecer um espaço social distinto" por meio de uma combinação da autoincorporação aos Estados Unidos unida à manutenção e desenvolvimento de um patrimônio e uma identidade culturais distintos (Flores e Benmayor 1997b: 1-2). Seus principais interlocutores são os movimentos sociais chican@s e latin@s. Seus admiradores incluem o jornal Fresno Bee e muitas das ideias foram divulgadas no The New York Times como parte de debates sobre o multiculturalismo nas universidades (Rosaldo, 1997; Flores e Benmayor, 1997a; Rodriguez e Gonzales, 1995; A Campus Forum, 1990). Rosaldo entende a cidadania cultural como um "paradoxismo deliberado" que estabelece uma ponte entre diferenças e semelhanças ao exigir igualdade econômica e política na base comum da manutenção da identidade e do exercício do "pertencimento pleno" à comunidade geral. Ele afirma que a dificuldade em estimular o voto das minorias nos Estados Unidos e os baixos índices de naturalização de imigrantes de minorias não-asiáticas (nos anos 1990, 57,6\% dos imigrantes asiáticos se tornaram cidadãos norte-americanos, contra $32,2 \%$ de latinos [Aleinikoff 20oo: 130]) podem ser abordados fomentando múltiplas afinidades entre idiomas, lugares ou costumes "antigos" $e$ os países adotados. Essa linha de pensamento está refletida na Constituição Indiana que, por um lado, impõe um código criminal comum e, por outro, a legislação civil reconhece as culturas minoritárias, um legado de milhares de anos durantes os quais o Dharmashastra foi o principal instrumento legislativo, governando por meio de identidades coletivas em lugar de direitos individuais. Esse conceito de cidadania também é compartilhado pelo Instituto para Educação da UNESCO, que enfatiza tanto direitos humanos coletivos quanto individuais e entende a cidadania cultural como um avanço e um antídoto frente aos ideais do assimilacionismo (1999).

Em terceiro lugar, encontram-se o teórico político radicado no Canadá, Kymlicka e vários colegas anglo-americanos liberais e comunitaristas ligeiramente heterodoxos. Eles buscam uma reaproximação entre a maioria branca, o "multiculturalismo imigrante" (novos migrantes voluntários, que requerem poucos direitos culturais) e o "nacionalismo das minorias" (os povos nativos, os despossuídos e os oprimidos, que requerem muitos direitos culturais) com um conceito de cultura como suporte para a autonomia individual por meio do envolvimento tanto com histórias coletivas quanto individuais. Esta posição está em consonância com o histórico do Canadá como primeiro Estado democrático a estabelecer seu próprio sistema de cidadania e que pratica o multiculturalismo
1. Chicanos - de origem mexicana. Tejanos - pessoas de origem mexicana que vivem no Texas. 
de maneira oficial desde 1971. Os admiradores de Kymlicka incluem o diário The Wall Street Journal, o Programa de Desenvolvimento das Nações Unidas, onde ele trabalhou como principal consultor em seu primeiro programa cultural, em 2004, e o diretor das Nações Unidas especializado em povos indígenas, Rodolfo Stavenhagen que, em seu discurso de abertura no Congresso Internacional de Americanistas de 2003, falou sobre o efeito da concepção de Kymlicka, que consiste em passar do status de indigenismo para o de cidadania cultural (Kymlicka, 1995 e 2000; Jenson e Papillon, 2001; Zachary, 2000; Programa de Desenvolvimento das Nações Unidas, 2004; Chile-Indigenas, 2003).

Entre os interlocutores de Kymlicka se encontram Estados onde as questões sobre as minorias étnicas são relevantes. Quando a União Soviética se dividiu em quase vinte países, Moscou não se incomodou com a ideia de que 25 milhões de russos étnicos permanecessem no "estrangeiro próximo", como são definidas as antigas repúblicas soviéticas por Moscou (Rich, 2003). Suas antigas repúblicas tinham duas opções para lidar com essas minorias consideráveis e, muitas vezes, abastadas: propor um nacionalismo cultural retributivo que marginalizasse o idioma russo e estabelecesse critérios religiosos, raciais e linguísticos para a cidadania (o que fizeram a Estônia e a Letônia, deslocando os russos da posição de "estabelecimento de agenda cultural da esfera pública" e relegando-os à esfera "privada/comunal”); ou adotar uma política civil pragmática que oferecesse direitos baseados em território, lealdade e trabalho (como foi feito na Ucrânia e no Cazaquistão). Os anteriores, então, tiveram que acalmar os conflitos resultantes por meio de escolas em russo e grupos culturais - cortesia de uma consultoria liderada por Kymlicka. Ao mesmo tempo, mudaram sua imagem cultural, renunciando à denominação bálticos e pós-soviéticos a favor de escandinavos e pré-União Européia. Não é necessário dizer que eles são estimulados a incorporar as minorias russas para melhorar suas possibilidades de se tornarem membros da União Européia e de receberem subsídios mediante adesão à Convenção Européia sobre Nacionalidade.

Enquanto Rosaldo et al. pretendem mudar o conceito de cidadania em favor dos interesses daqueles que são marginalizados por parte da maioria, Bennett et al. e Kymlicka et al. utilizam o conceito de cidadania para servir a um propósito geral que considere os interesses das minorias. Para Rosaldo, a cultura norte-americana distingue-se pela privação do direito de voto dos latinos. A diferença cultural prevalece de maneira considerável sobre o universalismo formal e o método padrão da filosofia liberal de manter as distâncias, onde as instituições estatais adotam uma postura neutra em relação à manutenção da cultura, é claramente insuficiente. Rosaldo é crítico do neoliberalismo e da filosofia liberal devido aos seus mitos sobre um indivíduo soberano e 
livre de qualquer dimensão cultural, que em realidade pressupõe um idioma e uma cultura comuns como base do Estado. Porque o tipo de "nacionalismo cívico" da filosofia liberal envolve uma obediência não somente ao Estado, mas também às imagens de nacionalismo que se estendem ao domínio público e privado (Runnymede Commission 2000: 19, 36). Kymlicka pensa de forma parecida, mas endossa o liberalismo, sempre e quando os Estados protejam as minorias - como uma questão de justiça e interesse pessoal. Para Bennett, a cultura é um conjunto de ferramentas vitais cujo valor está no alcance de objetivos concretos e que, portanto, não são fins expressivos em si mesmos. Ele entende o governo como um projeto que constitui o indivíduo liberal, e não como algo que se apoia nele, e é agnóstico em relação a reivindicações de um indivíduo soberano. Por razões pragmáticas, as abordagens cosmopolitas de Bennett e Kymlicka permanecem arraigadas na nação, porque se supõe que ela possa proporcionar um limite de lealdade capaz de apelar aos bons sentimentos de seus habitantes.

O quarto grupo teórico, representado pela filósofa Amélie Oksenberg Rorty, é uma concepção neoliberal das três primeiras posições. Nesta visão, a conservação e desenvolvimento da cultura deveriam ser consequência do acesso universal à educação, uma "condição fundamental para a participação livre e igualitária do cidadão na vida pública". Rorty se opõe ao financiamento público para sustentar normas culturais religiosas ou familiares, defendendo, em lugar disso, um programa que gere cidadãos cosmopolitas flexíveis que aprendam sobre seu país e sobre seus "vizinhos globais" (1995: 162, 164). O argumento de Rorty é uma reformulação culturalista de um conceito de capital humano mais próprio da Cosa Nostra, segundo o qual a função do investimento público em formação consiste em maximizar a utilidade do indivíduo, linha de pensamento com conexões às reivindicações de Bennett para que os cidadãos aprendam um conjunto de competências culturais. Ela rejeita a consciência transcultural como componente necessário de uma boa cidadania e justiça, mas a endossa como uma boa estratégia do ponto de vista econômico. Essa posição está alinhada com a do Programa de Desenvolvimento das Nações Unidas, que argumenta que "as sociedades com diversidade cultural" não são o feliz resultado da erradicação da pobreza, mas sim os requisitos necessários para isso (2004: v). Claramente, o enfoque instrumentalista de Rorty pode levar à extinção da cultura, apesar de todo seu cosmopolitismo.

O quinto grupo fundamental que teoriza o conceito de cidadania cultural engloba todas essas lógicas e trata-se do Relatório sobre o Futuro de uma Grã-Bretanha Multiétnica (200o), elaborado por uma comissão da fundação Runnymede do Reino Unido (2000). Seu presidente era Bhikhu Parekh, teórico 
político e futuro membro da Câmara dos Lordes britânica, e Stuart Hall, a segunda figura pública da comissão na mídia britânica. A comissão examinou o racismo dentro das instituições nacionais de cultura, educação, forças de segurança e assistência social. As reações populistas que o trabalho provocou nos dão uma ideia do quão profundamente arraigados se encontram os conflitos culturais na cidadania: "sandices pseudomarxistas"; "bobagens sem cabimento"; "um insulto à nossa história e inteligência" (British' is Already, 2000). Os autores foram acusados de "falta de lealdade e afeto para com a Grã-Bretanha" (Parekh, 2001). O jornal Daily Mail reagiu elaborando uma "lista de dez heróis brancos mortos do último milênio" (Seaford 2001: 108). William Hague, o então líder do Partido Conservador, ridicularizou o Relatório dizendo que era um indício da "tirania do politicamente correto" da esquerda e de sua “...violação da cultura e da história britânicas" (2000: 28), enquanto o jornal escocês The Scotsman o chamou de "uma grotesca calúnia contra a população desta terra e um perverso rascunho para a destruição do nosso país" (Warner, 2000). Jack Straw, então Ministro do Interior britânico e, mais tarde, um notório fomentador da guerra no Afeganistão e no Iraque, negou qualquer conexão entre a identidade britânica e o racismo branco. Isso indica o quanto está em jogo nesses debates, um alcance além das especificações técnicas das intervenções de políticas culturais descritas por Bennett, do feliz multiculturalismo vernáculo defendido por Rosaldo ou da tentativa de Kymlicka de que todos "se relacionem bem" nos ambientes póssocialistas, recentemente livres e chauvinistas, ou da crença de Rorty em um programa inclusivo motivado por um autointeresse erudito.

Tudo isso se torna muito mais claro no sexto grupo, que aborda os limites do neoliberalismo. Amy Chua, uma advogada que trabalha a partir de uma perspectiva de estudos étnicos comparativos - e que publica em uma editora comercial norte-americana, e não em uma editora acadêmica -, pesquisa, dentro do contexto global, a confluência do neoliberalismo, das oligarquias econômicas pertencentes a minorias étnicas e da democracia: ou seja, o que acontece quando as minorias abastadas sofrem fortes reações populares contra seu poder econômico por meio da rejeição majoritária da diferença cultural. Enquanto a economia enriquece "a minoria que domina o mercado, o processo de democratização eleva a voz e o poder políticos de uma maioria frustrada" (2003: 124). Como afirma Chua de maneira provocativa e com o claro pesar de uma fã tanto do capitalismo como da democracia, trata-se de um dispositivo "que converte a democracia de livre mercado em uma máquina geradora de conflitos étnicos" (Ibid.: 6). Seu trabalho descreve com detalhes a maneira como as maiorias autóctones protestam contra suas debilidades. Em uma confusão de classe, corrupção e raça, 
as minorias dominantes do mercado, juntamente com seus sócios investidores estrangeiros, invariavelmente chegam ao controle das joias da coroa da economia: petróleo na Rússia e na Venezuela, diamantes na África do Sul, prata e estanho na Bolívia, jade, madeira de teca e rubis na Birmânia" (Ibid.: 10).

Os mercados livres concentram a riqueza de maneira desproporcional, enquanto as democracias concentram a política de maneira proporcional. A mediação dos direitos políticos e seu oposto econômico ocorrem por meio da diferença cultural, com um resultado revolucionário. Os horrores de Ruanda e da ex-Iugoslávia nos anos 1990 ilustram o que acontece quando um populismo étnico-nacionalista, baseando-se na diferença cultural, recorre ao ressentimento da maioria para suprimir o poder econômico da minoria (Ibid.: 11-13, 16-17).

O sétimo e mais poderoso grupo deriva do trabalho do historiador especializado em Oriente Médio e ativista antipalestino profissional Bernard Lewis e do cientista político da Guerra Fria, arquiteto da Guerra do Vietnã e defensor da política do inglês como idioma único Samuel Huntington. Nos pós-soviéticos anos 1990, esses dois homens lançaram mão da cultura para explicações geopolíticas. Lewis (1990) cunhou a expressão "choque de civilizações" para definir a diferença, segundo ele, entre a separação da igreja e do Estado que havia gerado os êxitos dos Estados Unidos em contraste com sua convergência nas nações islâmicas, que havia produzido a posição de subordinação daqueles países. Esqueça o apoio ianque aos antidemocratas autoritários e aos golpes de Estado cujo objetivo era a exploração do petróleo - o ressentimento islâmico está relacionado somente com a insistência dos Estados Unidos em que "a César o que é de César e a deus o que é de deus". Huntington usou a expressão "choque de civilizações" para argumentar que os futuros conflitos mundiais históricos não seriam "primariamente de caráter ideológico ou econômico", mas "cultural” (1993: 22). Essa linha de pensamento desmaterializa a política - e, mais especificamente, justifica as políticas e programas do governo e das corporações norte-americanos como algo somente superficialmente relevante para o ódio que existe em relação a este país fora de suas fronteiras.

As grotescas generalizações dos gêmeos do choque receberam enorme atenção durante a década passada, notavelmente depois do atentado de 11 de setembro de 2001. Nos Estados Unidos, a grandiosidade olímpica de Huntington seduziu a mídia burguesa, sempre disposta a adotar uma visão de "mundo de desenho animado onde Popeye e Brutus se espancam mutuamente" (Said, 2001). Os jornalistas promovem a ideia de uma batalha apocalíptica entre o bem e o mal representada pela divisão entre os Estados Unidos e o Islã, baseando todos os argumentos sobre as diferenças entre o Ocidente e a cultura islâmica nas teses de Lewis e Huntington. Na imprensa diária e revistas de opinião semanais e 
mensais, os conflitos supranacionais são atribuídos ao Islã como a face oposta à liberdade e à tecnologia, nunca como os atos de grupos desfavorecidos contra grupos dominantes. O jornal The New York Times e a revista Newsweek deram espaço para que Huntington explicasse o que havia ocorrido sob o prisma de sua tese, enquanto outros veículos adotaram essa linha de pensamento como uma reivindicação do império, desde a suposta Nova Esquerda (a revista Dissent e outras publicações progressistas que compartilham este ponto débil ianque quando se trata dessa região) até líderes comunitaristas e imprensa neoliberal, como a revista The Economist. Depois dos ataques, os líderes árabes se reuniram para discutir o impacto das ideias de Lewis e Huntington e o primeiro-ministro italiano Silvio Berlusconi as evocou. Quando a ocupação norte-americana no Iraque entrou em seu terceiro ano, o livro tornou-se leitura obrigatória para os comandantes militares e oficiais subalternos seniores (juntamente com V.S. Naipaul e Islã para Iniciantes) (Rusciano, 2003; Said, 2001; Schmitt, 2005).

No entanto, nem todos se entusiasmaram com essas ideias. No prefácio da importante Declaração sobre Diversidade Cultural da UNESCO, seu diretor-geral incluiu uma réplica expressa a elas (Matsuura, 2001) e o cartunista Máximo, do diário espanhol El País, construiu de maneira dramática o seguinte diálogo sobre as Torres caídas: mediante a afirmação "Choque de ideas, de culturas, de civilizaciones", lia-se a resposta "Choques de desesperados contra instalados" ("Choque de desesperados contra o establishment") (citado em García Canclini 2002: 16). O jornal israelense $\mathrm{Ha}$-aretz qualificou o "caráter hegemônico" das teses de Lewis e Huntington como um "grande triunfo" para a Al Qaeda, e o Arab News acertadamente as classificou como "Armagedom disfarçado de ciência social" (citado em Rusciano 2003: 175). Diversos estudos refutaram as disparatadas afirmações de Lewis e Huntington sobre conflitos étnicos em crescimento desde a Guerra Fria e sobre uma cultura islâmica unitária em contraposição a um Ocidente unitário. Tais alegações ignoraram completamente os conflitos relacionados a recursos econômicos, propriedades, água e política (Fox, 2002; Norris e Inglehart 2003: 203; Programa de Desenvolvimento das Nações Unidas, 2004). A tese do "choque de civilizações" não funciona quando aplicada ao apoio do Irã à Rússia contra os rebeldes chechenos e ao conflito entre Índia e Paquistão ou à atitude norte-americana em relação à Guerra Irã-Iraque. Mas que importam os detalhes históricos do mundo quando se oferecem "relações internacionais sem política" (Abrahamian 2003: 535).

As posteriores críticas de Huntington aos hispano hablantes dos Estados Unidos (2004) ganharam o apoio do Centro para Estudos de Imigração e de uma bateria de intelectuais da política pop bastante influentes, cuja erudição está ultrapassada há muito tempo, se é que em algum momento chegaram a 
ter alguma. Entre os coristas se encontravam Zbigniew Brzezinski, veterano da Guerra Fria; Lucian Pye, fundador de estudos de área da velha-guarda; James Q. Wilson, servidor dos governos Nixon e Reagan e defensor da teoria das "janelas quebradas", que defende punições severas para pequenos delitos; Fareed Zakaria, jornalista reacionário da revista Newsweek; e os agudos cidadãos culturais do coletivo $<$ vdare.com $>$, autoproclamados guardiões da chama de uma tribo perdida de brancos ianques. $\mathrm{O}$ estranho fato de que somente $21 \%$ dos latinos de terceira geração se identificam com seus países de origem, que a maioria dos latinos nascidos nos Estados Unidos tem visões muito mais conservadoras sobre a imigração do que os recém-chegados ao país e que a terceira geração de latinos é predominantemente monolíngue no idioma inglês não deve ser levado em consideração para que estes tipos de disparates prosperem - para não falar do fato de que os primeiros colonizadores, tão adorados por Huntington, cujos costumes e valores são supostamente essenciais para os EUA, estavam muito mais preocupados em queimar bruxas, vaiar adúlteras e vestir roupas e perucas afetadas do que com qualquer outra coisa. $\mathrm{O}$ argumento é moralmente, pragmaticamente e empiricamente errado. Mas é cultural.

\section{CONCLUSÃO}

\begin{tabular}{|c|c|c|c|c|}
\hline AUTOR & DISCIPLINA & $\begin{array}{l}\text { CAMPO DE } \\
\text { INFLUÊNCIA }\end{array}$ & $\begin{array}{l}\text { SUBJETIVIDADE } \\
\text { LIBERAL }\end{array}$ & POLÍTICA CULTURAL \\
\hline TONY BENNETT & $\begin{array}{l}\text { Sociologia/Estudos } \\
\text { Culturais }\end{array}$ & $\begin{array}{l}\text { Política Cultural } \\
\text { Australiana/Européia }\end{array}$ & $\begin{array}{l}\text { Criada mediante } \\
\text { competências culturais }\end{array}$ & Engenharia social \\
\hline RENATO ROSALDO & $\begin{array}{l}\text { Estudos Culturais/ } \\
\text { Antropologia }\end{array}$ & $\begin{array}{l}\text { Estudos Chicanos (Eua), } \\
\text { Fresno Bee, The New } \\
\text { York Times }\end{array}$ & $\begin{array}{l}\text { Enfraquecida pela } \\
\text { consciência da pobreza }\end{array}$ & Vernaculismo e táticas \\
\hline WILL KYMLICKA & Teoria Política & $\begin{array}{l}\text { Estados Bálticos, Canadá, } \\
\text { The Wall Street Journal }\end{array}$ & $\begin{array}{l}\text { Enriquecida pela } \\
\text { migração e pela pobreza }\end{array}$ & Igualdade linguística \\
\hline BHIKHU PAREKH & Teoria Política & $\begin{array}{l}\text { Comissão Britânica, } \\
\text { Debates Indianos }\end{array}$ & $\begin{array}{l}\text { Enfraquecida pela } \\
\text { imigração }\end{array}$ & $\begin{array}{l}\text { Desinstitucionalização } \\
\text { do Racismo }\end{array}$ \\
\hline $\begin{array}{l}\text { AMÉLIE OKSENBERG } \\
\text { RORTY }\end{array}$ & Filosofia & Neoliberalismo & $\begin{array}{l}\text { Criada como capital } \\
\text { humano }\end{array}$ & $\begin{array}{l}\text { Formação para a } \\
\text { concorrência global }\end{array}$ \\
\hline $\begin{array}{l}\text { BERNARD LEWIS E } \\
\text { SAMUEL HUNTINGTON }\end{array}$ & $\begin{array}{l}\text { História e Relações } \\
\text { Internacionais }\end{array}$ & $\begin{array}{l}\text { Mídia Norte-Americana } \\
\text { e Política Externa }\end{array}$ & $\begin{array}{l}\text { Forjada pela tradição } \\
\text { ocidental }\end{array}$ & $\begin{array}{l}\text { Costumes e valores } \\
\text { judaico-cristãos }\end{array}$ \\
\hline AMY CHUA & Direito & Cultura pública dos EUA & $\begin{array}{l}\text { Enfraquecida pela } \\
\text { desigualdade étnica }\end{array}$ & $\begin{array}{l}\text { Antinacionalismo, } \\
\text { filantropia }\end{array}$ \\
\hline
\end{tabular}

A tabela acima resume as posições descritas anteriormente. Tanto o terreno árido de Bennett quanto as esferas úmidas de Rosaldo, Kymlicka, Parekh e Chua ilustram a improbabilidade de varrer da história as diferenças entre povos indígenas, colonizadores dominantes e minorias migrantes - no entanto, 
Rorty idealiza uma fusão de capital humano a partir de todos os conceitos anteriormente expostos e Lewis e Huntington oferecem uma justificativa ideológica para esvaziar a história material e explicar a hegemonia ocidental em termos culturais. Parece que as competências de Bennett, as resistências de Rosaldo e os relativismos de Kymlicka, Parekh e Chua podem ser acomodados (embora com suas retóricas suavizadas em algumas passagens e fortalecidas em outras) dentro de uma concepção de mundo neoliberal, da qual os limites são estabelecidos por meio do hiperculturalismo e do nacionalismo encoberto dos teóricos do "choque". Tudo para defender a dimensão cultural no mais cultural dos mundos possíveis, sendo que o ponto crucial é uma mão-de-obra eficiente e efetiva, cujo cosmopolitismo se administre dentro do contexto do respeito pela diferença, assegurando a vantagem individual em um mercado de trabalho globalmente competitivo.

Cada uma dessas propostas apresenta linhas de pensamento que são, ao mesmo tempo, extremamente práticas e altamente emocionais, profundamente populistas e declaradamente técnicas. Como tal, inevitavelmente esbarram em contradições. Bennett tem que lidar com a incomensurabilidade das prescrições neoliberais e estadistas. Rosaldo tem que se reconciliar com o fato de que o governo é, frequentemente, o tribunal de apelação para protestos vernáculos. Kymlicka e Parekh tem que assumir os limites econômicos da filosofia liberal. Rorty deve ocupar-se da natureza obstinadamente coletivista e híbrida da cultura e do fato de que o neoliberalismo não é mais metacultural que qualquer outra forma de pensamento. Chua tem que reconhecer a desigualdade constitutiva e a brutalidade do capitalismo. Lewis e Huntington têm que explicar a realidade da política norte-americana para o Oriente Médio e contar passagens históricas de maneira muito mais precisa do que suas grandiosidades lhes permitirão.

Para os reacionários, a cidadania cultural significa uma perda da unidade nacional e espiritual, pois representa a vitória do sectarismo e do secularismo sobre o patriotismo e a superstição. Para a esquerda e para os estudos culturais, a cidadania cultural está relacionada com a manutenção, desenvolvimento e intercâmbio da linhagem cultural - uma celebração da diferença que também é uma crítica do status quo. Para a direita neoliberal, ela oferece um novo conjunto de nichos mercadológicos e eclesiásticos e espaços de autogoverno. Minha preocupação é que na esquerda cultural conseguimos o que queríamos - situar cultura no centro da política e das análises sociopolíticas. O problema é que isso não aconteceu através da Queer Nation ou de Stuart Hall, mas sim através do consumismo e de Samuel Huntington. Precisamos rearticular a cultura em torno da economia e da política com "P" maiúsculo, e não como uma esfera de idealização antimaterialista e ilusória. 
As doutrinas de cidadania cultural podem ser efetivas para conseguir um mundo mais igualitário se elas rejeitarem o tecnicismo, o utopismo, o liberalismo, o nacionalismo e o neoliberalismo que operam no conceito de cidadania cultural de sempre e reconhecerem que dependem tanto dos projetos de desregulamentação quanto dos movimentos sociais de esquerda. Em resposta ao teoricismo e à tecnocracia do neoliberalismo, cabe apontar os sistemas de orçamento participativo/popular colocados em prática por governos de esquerda regionais e urbanos em Kerala, Cidade do México e Porto Alegre nos últimos quinze anos, e o "sindicato cidadão" do Brasil. Podemos formar alianças estratégicas com opositores do neoliberalismo, como George Soros, que fez sua fortuna nos mercados financeiros, mas atualmente reconhece que a "intensificação desenfreada do capitalismo laissez-faire e a disseminação do sistema de valores do mercado para todas as áreas da vida estão colocando em perigo nossa sociedade aberta e democrática" (1997).

No seu artigo "Ten Dispatches About Place", de 2005, o célebre crítico cultural John Berger responde à pergunta "Você ainda é marxista?". Depois de repassar a incomparável "devastação causada pela busca do lucro", ele conclui que "Sim, ainda sou, entre outras coisas, marxista". Estas "outras coisas" são extremamente importantes e referem-se a formas de vida cruciais que operam com relativa independência da economia. Mas só podemos nos dedicar a estas "outras coisas" se, ao mesmo tempo, nos ocupamos dos aspectos igualmente cruciais tratados aqui. Então, uma rápida pergunta: você ainda é um culturalista? $\mathbf{M}$

\section{REFERÊNCIAS}

A Campus Forum on Multiculturalism. New York Times: 5, 09/12/1990.

ABRAHAMIAN, Ervand. The US Media, Huntington and September 11. Third World

Quarterly 24, no. 3: 529-44, 2003.

ALBA, Richard. Language Assimilation Today: Bilingualism Persists More Than in the Past, but English Still Dominates. Center for Comparative Immigration Studies, University of California, San Diego. Working Paper 111, 2004.

ALEINIKOFF, T. Alexander. Between Principles and Politics: U. S. Citizenship Policy. In.: From Migrants to Citizens: Membership in a Changing World. Ed. T. Alexander Aleinikoff and Douglas Klusmeyer. Washington: Carnegie Endowment for International Peace. 119-72, 2000.

BENNETT, Tony. Culture: A Reformer's Science. London: Sage, 1998.

. Differing Diversities: Transversal Study on the Theme of Cultural Policy and

Cultural Diversity. Strasbourg Cedex: Council of Europe Publishing, 2001.

BERGER, John. “Ten Dispatches About Place.” Le Monde Diplomatique, 2005.

British is Already Inclusive and Elastic. In: Independent: 3, 12/10/200o. 
CASTLES, Stephen e DAVIDSON, Alastair. Citizenship and Migration: Globalization and the Politics of Belonging. Basingstoke: Macmillan, 2000.

Chile-Indigenas: Relator de la ONU se reunira con indigenas chilenos. In: Spanish Newswire Services, 18/07/2008.

CHUA, Amy. World on Fire: How Exporting Free Market Democracy Breeds Ethnic Hatred and Global Instability. New York: Doubleday, 2003.

Citizenship and Cultural Policy. In: American Behavioral Scientist 43, no. 9, 2000.

DOWNEY, John e MURDOCK, Graham Murdock. The Counter-Revolution in Military Affairs: The Globalization of Guerrilla Warfare. In.: War and the Media: Reporting Conflict 24/7. Ed. Daya Kishan Thussu and Des Freedman. London: Sage Publications. 70-86, 2003.

FLORES, William V. e BENMAYOR, Rina. Ed. Latino Cultural Citizenship: Claiming Identity, Space, and Politics. Boston: Beacon Press, 1997 a.

. "Constructing Cultural Citizenship." Latino Cultural Citizenship: Claiming Identity, Space, and Politics. Ed. William V. Flores and Rina Benmayor. Boston: Beacon Press. 1-23, 1997 b.

FOX, Jonathan. Ethnic Minorities and the Clash of Civilizations: A Quantitative Analysis of Huntington's Thesis. British Journal of Political Science 32, no. 3: 415-35, 2002.

FUENTES, Carlos. Huntington and the Mask of Racism. (Trad.Thomas D. Morin). New Perspectives Quarterly: 77-81, 2004.

GARCÍA CANCLINI, Néstor. Latinoamericanos Buscando Lugar en este Siglo. Buenos Aires: Paidós, 2002.

HAGUE, William. Why I am Sick of the Anti-British Disease. In.: Daily Telegraph: 28, 13/10/2000.

HALLIDAY, Fred. The World at 200o: Perils and Promises. Basingstoke: Palgrave, 2001. HUTINGTON, Samuel P. The Clash of Civilizations? In.: Foreign Affairs 72, no. 3: 2228, 1993.

. ¿Quiénes somos? Los desafíos a la identidad nacional estadounidense. (Trad. Albino Santos Mosquera. México: Paidós.

Jenson, Jane and Martin Papillon). (2001). The Changing Boundaries of Citizenship: A Review and a Research Agenda. Canadian Policy Research Networks, 2004.

KYMLICKA, Will. Multicultural Citizenship: A Liberal Theory of Minority Rights. Oxford: Oxford University Press, 1995.

. "A North American View." Journal of Ethnic and Migration Studies 26, no. 4: 723-31, 2000.

LEWIS, Bernard. The Roots of Muslim Rage: Why so Many Muslims Deeply Resent the West, and Why Their Bitterness will not be so Easily Mollified. In.: Atlantic Monthly: 47-58, set. 1990.

LOMNITZ, Claudio. American Soup. In.: Boston Review, 10/03/2005. 
MARTIIN-BARBERO, Jesús. Introducción. In: Imaginarios de Nación: Pensar en Medio de la Tormenta. Ed. Jesús Martin-Barbero. Bogotá: Ministerio de Cultura. 7-10, 2001.

MILlER, Toby. Cultural Citizenship: Cosmopolitanism, Consumerism, and Television in a Neoliberal Age. Philadelphia: Temple University Press, 2007 a.

. Culture, Dislocation, and Citizenship. In.: Global Migration, Social Change, and Cultural Transformation. Ed. Emory Elliott, Jasmine Payne, and Patricia Ploesch. New York: Palgrave Macmillan. 166-86, 2007 b.

NORRIS, Pippa e INGLEHART, Ronald Inglehart. Public Opinion Among Muslims and the West. In.: Framing Terrorism: The News Media, the Government, and the Public. Ed. Pippa Norris, Montague Kern, and Marion Just. New York: Routledge. 203-28, 2003.

RORTY, Amélie Oksenberg. Rights: Educational, not Cultural. In.: Social Research 62, no. 1: 161-70, 1995.

PAREKH, Bhikhu. Rethinking Multiculturalism: Cultural Diversity and Political Theory. Basingstoke: Palgrave, 2000.

"Reporting on a Report." Keynote Address to the Political Studies Association of the United Kingdom, 2001.

PORTES, Alejandro. Introduction: The Debates and Significance of Immigrant Transnationalism. In.: Global Networks 1, no. 3: 181-93, 2001.

PEDRO, Jesús Prieto de. Democracy and Cultural Difference in the Spanish Constitution of 1978. Democracy and Ethnography: Constructing Identities in Multicultural Liberal States. Ed. Carol J. Greenhouse with Roshanak Kheshti. Albany: State University of New York Press. 61-80, 1999.

RAWLS, John. A Theory of Justice. Cambridge, Mass.: The Belknap Press of Harvard University Press, 1971.

RICH, Vera. The Price of Return. In.: Index on Censorship 32, no. 3: 82-86, 2003.

RODRIGUEZ, Roberto e GONZALES, Patrisia. Cultural Idea for Citizenship is Catching on. In.: Fresno Bee: B5, 15/05/1995.

ROSALDO, Renato. Cultural Citizenship and Educational Democracy. Cultural Anthropology 9, no. 3: 402-11, 1994.

. Cultural Citizenship, Inequality, and Multiculturalism. In.: Latino Cultural Citizenship: Claiming Identity, Space, and Politics. Ed. William V. Flores and Rina Benmayor. Boston: Beacon Press. 27-38, 1997.

Runnymede Trust Commission. The Future of Multi-Ethnic Britain. London: Profile, 2000.

RUSCIANO, Frank Louis. Framing World Opinion in the Elite Press. In.: Framing Terrorism: The News Media, the Government, and the Public. Ed. Pippa Norris, Montague Kern, and Marion Just. New York: Routledge. 159-79, 2003.

SAID, Edward. We all Swim Together. New Statesman: 20, 15/10/2001. 
SCHMITT, Eric. New U.S. Commander Sees Shift in Military Role in Iraq. In.: New York Times: 10, 16/01/2005.

SEAFORD, Helen. The Future of Multi-Ethnic Britain: An Opportunity Missed. In.: Political Quarterly 72, no. 1: 107-12, 2001.

SOROS, George. The Capitalist Threat. Atlantic Monthly, fev. 2009.

UNESCO Institute for Education. Cultural Citizenship in the $21^{\text {st }}$ Century: Adult Learning and Indigenous Peoples, 1999.

United Nations Development Programme. Human Development Report 2004: Cultural Liberty in Today's Diverse World, 2004.

WARNER, Gerald. British Identity Threatened by Phony Race Relations Industry. The Scotsman: 20, 15/10/2000.

ZACHARY, G. Pascal. "A Philosopher in Red Sneakers Gains Influence as a Global Guru." Wall Street Journal: B1, B4, 28/03/2000.

Traduzido do inglês por Daniela Pintão

Artigo recebido em 3 de dezembro de 2010 e aprovado em 4 de março de 2011. 